\title{
Validation of Thin-Layer Chromatography-Bioautographic Method for Determination of Streptomycin
}

Isnaeni*, Andri Astuti, Muhammad Yuwono

Fakultas Farmasi, Universitas Airlangga, Surabaya

*Corresponding author: isna.yudi@gmail.com

\begin{abstract}
Background: A simple bio-assay for determination of streptomycin hyphenated with planar chromatography techniques was developed. Objective: This study aims to validate the method for identification and determination of streptomycin in injection preparations with TLC-bioautography. Methods: Thin Layer Chromatography (TLC) was performed on the silica Gel GF-254 using $\mathrm{KH}_{2} \mathrm{PO}_{4}$ solution as mobile solvent. The visualization was performed by spraying 2\% resorcinol. Direct bi autography was developed using Escherichia coli ATCC 25922 as a bacterial test, grown on the nutrient agar medium at $37^{\circ} \mathrm{C}$ for 24 hours. The method was validated corresponding to linearity, limit of detection (LOD), intra day precision, and accuracy parameters. The accuracy was measured using streptomycin injection as a sample. Results: The Results showed that the $\mathrm{KH}_{2} \mathrm{PO}_{4}$ solution at $7.5 \%$ concentration was found to be the optimized solvent with $R f$ value of 0.5 . The linear equation was $y=$ $10.176 x+4.046$ at $150-350 \mu \mathrm{g} / \mathrm{mL}$ concentration range with the linearity coefficient, Limit of Detection, accuracy, and variation coefficient were 0.9907; $40 \mathrm{ppm} ; 96.37 \pm 2.22 \%$ (with an RSD value of $2.31 \%$ ); and 1.63 respectively. Conclusion: The prospective TLC-bioautographic method was applied for the identification and determination of streptomycin in a preparation using a single eluent $\mathrm{KH}_{2} \mathrm{PO}_{4}$. The eluent system optimization remains necessary for the identification and determination of the mixture of streptomycin with other antibiotics, such as aminoglycoside groups.
\end{abstract}

Keywords: validation, TLC-bioautography, streptomycin

\section{INTRODUCTION}

TLC-bioautography is a method consisted of chromatographic separation and biological activity determination (Choma, 2005). The method is widely applied for detection of antimicrobial (Choma \& Edyta, 2011), antioxidant (Marston, 2011; Cheng \& $\mathrm{Wu}, 2013)$ and enzyme inhibitory activities (Gu et al., 2015). The TLC-bioautography of antimicrobial substances was performed based on the detection of compound in the chromatogram by using microorganisms as an indicator. Clear zone on the spot position indicates antimicrobial activity of the substances. Validation of the TLC-bioautography method with characteristic parameters namely selectivity, sensitivity, linearity, precision, recovery, and stability is performed by optimizing factors affected the analysis results such as plate type, time and temperature of incubation. The TLCbioautography method of commonly used for bioactivity screening purposed in natural products (Choma \& Edyta, 2011). The method validation for determination of streptomycin by TLC-bioautography has not been reported, although chromatogram profile of the aminoglycoside antibiotics using several solvent system has been reported by Claes \& Vanderhaeghe (1982).

Streptomycin belongs to aminoglycoside antibiotic that widely used to treat infectious diseases in human, animal as well as in plant agriculture (Shafqat $e t$ al., 2012). The antibiotic administrates in injection dosage form or powder for solution preparations (Wills, 2005). Determination of streptomycin and its derivatives by HPLC (Whall, 1981), LC-MS/MS (Pendela et al., 2009) and LC-MS (Hormazabal \& Ostensviko, 2013) TLC-Densitometry (Urszula et al., 2009) have been reported. The potency testing in the quality control laboratories is used for determination of aminoglycoside antibiotics such as streptomycin, kanamycin and gentamycin in the pharmaceutical dosage form. The method gives very simple, accurate, and reproducible results. Drug monitoring sometimes is needed to evaluate of effectiveness and side effect after the drug administrated to patient. In case, the drug exists in a mixture with other substances, a valid method is needed to obtain responsible of analysis results. The streptomycin is one of aminoglycoside antibiotics that still used as a first line anti-tuberculosis drug with side effect of nephrotoxicity and ototoxicity (Toman, 2004). Where possible, serum level should be 
monitored periodically. The aim of this research are to validate the TLC-bioautography method using single solvent system $\mathrm{KH}_{2} \mathrm{PO}_{4}$ solution for determination of streptomycin in the dry powder/small volume parenteral dosage form (injection). The result could be implemented for separation of the active compound (streptomycin) from its mixture not only in the dosage form but also in the specimens, like plasma and urine. The use of bacteria test for detecting streptomycin would be specific to distinguish from non-antibiotic compounds. The single solvent $\left(\mathrm{KH}_{2} \mathrm{PO}_{4}\right.$ solution) used is relatively safe and cheaper compared to organic solvent.

\section{MATERIALS AND METHODS}

\section{Chemicals and reagents}

Streptomycin sulphate (Sigma) and injection of streptomycin were commercially obtained. Potassium phosphate mono basic (Sigma), distilled water, Nutrient agar (Oxoid), Escherichia coli ATCC 25922 (Health Laboratory, Surabaya), and saline (Sodium chloride $0,9 \%$ ) solution.

\section{Thin layer chromatography bioautography}

A standard stock solution of streptomycin (100 mg/100 mL) was prepared by dissolving $100 \mathrm{mg}$ streptomycin powder in $100 \mathrm{~mL}$ distilled water. Concentration of the standard $1000 \mu \mathrm{g} / \mathrm{mL}$ was diluted with distilled water to obtain $30,40,50,60,70$, and $80 \mu \mathrm{g} / \mathrm{mL}$ for determination of LOD, while for determination of linearity was performed by dilution of the standard solution to obtain 150, 200, 250, 300, and $350 \mu \mathrm{g} / \mathrm{mL}$ concentration. The sample solution was obtained from the dry powder dosage form (2-gram streptomycin powder in vial), prepared, diluted, and analyzed by the same method as a standard solution. The mobile solvent was prepared in several concentrations for optimization and to choose concentration of the $\mathrm{KH}_{2} \mathrm{PO}_{4}$ solution $5 \%$ or $7.5 \%$.

Suspension of Escherichia coli ATCC 25922 was prepared by growing it in a slant medium (nutrient agar, at $35 \pm 2{ }^{\circ} \mathrm{C}$ for $24 \mathrm{~h}$ ). The growth cells were suspended in a saline sterile solution and diluted to give a suspension with $25 \pm 2 \%$ transmittance at $580 \mathrm{~nm}$ using a $1 \mathrm{~cm}$ absorption cell and $0.9 \% \mathrm{NaCl}$ sterile as a blank solution. Seed layer medium was prepared by inoculating $5 \mu \mathrm{L}$ cell suspension in $7 \mathrm{~mL}$ of nutrient agar medium at $48{ }^{\circ} \mathrm{C}$ (Susanti et al., 2009); which then overlaid on the surface of nutrient agar based layer medium.
The chromatography of antibiotic standard and samples solution was performed on silica gel $\mathrm{F}_{254}$ (Merck), with the $\mathrm{KH}_{2} \mathrm{PO}_{4}$ solution as the mobile solvent (Isnaeni, 2005). The chromatogram of a developed TLC plate was contacted on a surface of the nutrient agar media inoculated by Escherichia coli ATCC 25922 as a test bacterium. (Susanti et al., 2009). The mobile solvent was $7.5 \% \quad \mathrm{KH}_{2} \mathrm{PO}_{4}$ solution. An amount of $10 \mu \mathrm{L}$ of each sample and standard solution were applied on the TLC plates in a spot and developed using the mobile solvent system. The plates were dried to remove solvent residue on the plates (Suleimana et al., 2010). Resorcinol solution (2\%) was used as detection reagent to observe position of purple color spot on the chromatogram plate.

Furthermore, the different chromatography plates free from spray reagent was placed on the surface of test medium containing the suspension of Escherichia coli ATCC 25922 and then storage in the refrigerator for 1 hour to allow diffusion of active substances on the test media. The growth of bacterium was appeared on the surface of the test media after incubation overnight, excluding spots of the streptomycin. The diameters $(\mathrm{mm})$ of the clear zone around the spots were measured by calibrated digital caliper (Susanti et al., 2009).

\section{Method validation}

The method was validated according to the International Conference on Harmonization ( $\mathrm{ICH}$, 2005) for evaluation of the performance attributes like LOD, linearity, accuracy and precision. The LOD is the minimum amount of analyte that can reliably inhibit the test microorganisms. This attribute was done by assaying a serial of standard solution at $30-80 \mu \mathrm{g} / \mathrm{mL}$ range of concentration. This characteristic is applicable for Minimum Inhibition Concentration (MIC) determination. The linearity was evaluated through three independent assays using linear regression analysis and calculated by a leastsquares method for five doses of the reference substance. The accuracy means the ability of the method to measure the actual or true value of the analyte. The test was repeated in three consecutive days. Three concentration levels, covering $80 \%$ to $120 \%$ of the selected range of 250,300 , and $350 \mu \mathrm{g} / \mathrm{mL}$, were tested each day. The precision is the degree of agreement among individual test results when the method is applied repeatedly to multiple samplings of a homogenized sample. This parameter was assessed through the repeatability and 
intermediate precision and expressed as the relative standard deviation (RSD).

\section{RESULTS AND DISCUSSION}

\section{Thin layer chromatography-bioautography}

The chromatogram of streptomycin standard solution gave $\mathrm{Rf}$ value of 0.50 and 0.33 at $7.5 \%$ and $5 \%$ concentration of $\mathrm{KH}_{2} \mathrm{PO}_{4}$ solvent, respectively. It was found that clear zone was appearance sharply at $10 \mu \mathrm{L}$ and $15 \mu \mathrm{L}$ containing $0.8 \mu \mathrm{g}$ and $1.2 \mu \mathrm{g}$ streptomycin respectively (Figure 1) for both before and after the plate development (Table 1). It should be noted that the clear zone was not detected on the chromatogram at $5 \mu \mathrm{L}$ sample solution for all concentrations of the eluents.

Table 1. Optimization of sample tested volume on contact bioautography qualitatively with E.coli ATCC 25922

\begin{tabular}{ccc} 
& 25922 \\
\hline & $\begin{array}{c}\text { Appearance of clear zone } \\
\text { inhibition (qualitatively) at } \\
\text { Vol. of } \\
\text { concentration }(\mu \mathrm{g} / \mathrm{mL}) \text { of }\end{array}$ \\
\cline { 2 - 2 } & \begin{tabular}{ccc}
$80 \quad 100 \quad 120 \quad 140 \quad 160$ \\
\cline { 2 - 2 }
\end{tabular} \\
$\begin{array}{c}\text { Before and after the plate } \\
\text { development }\end{array}$ \\
\hline 5 & negative \\
10 & positive \\
& positive \\
\hline
\end{tabular}

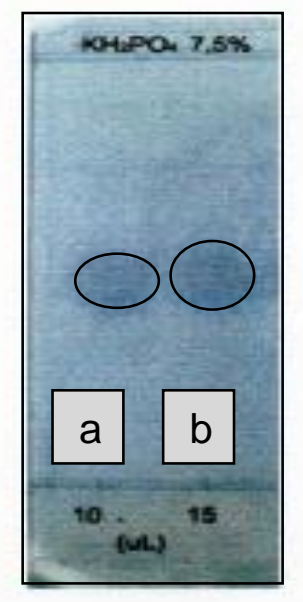

Figure 1. Bioautogram of Streptomycin sulphate on silica gel $\mathrm{GF}_{254}$ plate; Eluted by $7.5 \% \mathrm{KH}_{2} \mathrm{PO}_{4}$ solution with $E$. coli ATCC 25922 as a test bacteria; (a) $10 \mu \mathrm{L}$ sample and (b) $15 \mu \mathrm{L}$ sample

\section{Method validation}

LOD

It was found that the LOD of streptomycin was $40 \mu \mathrm{g} / \mathrm{mL}$. This value was reflected as Minimum Inhibition Concentration (MIC) of the streptomycin (Table 2).

Table 2. The results of LOD evaluation on the bioautography of streptomycin sulphate with E.coli ATCC 25922

\begin{tabular}{cc}
\hline $\begin{array}{c}\text { Conc. of Samples } \\
(\mu \mathrm{g} / \mathrm{mL})\end{array}$ & $\begin{array}{c}\text { Diameter of clear zone } \\
\text { growth inhibition }(\mathrm{mm})\end{array}$ \\
\hline$<40$ & - \\
\hline 40 & $* 7.862$ \\
50 & 8.281 \\
60 & 8.883 \\
70 & 10.062 \\
80 & 10.241 \\
\hline * Diameter of hole/reservoir $=7 \mathrm{~mm}$ \\
\hline
\end{tabular}

\section{Linearity}

The standard solution at 150,200, 250, 300, and $350 \mu \mathrm{g} / \mathrm{mL}$ concentration was used as linearity test. The intra-day precision was determined by loading $10 \mu \mathrm{L}$ three standard solutions. $(n=3)$. The mean of the recorded clear zone diameter $(\mathrm{mm})$ was taken for calibration curve; which obtained by plotting against log concentration (Figure 2).

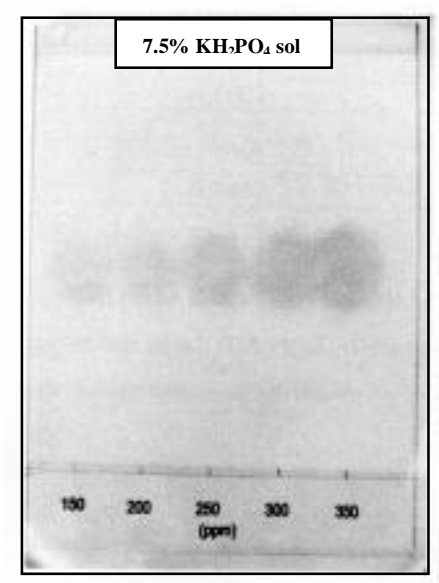

Figure 2. Linearity observed by bioautography on silica gel $\mathrm{F}_{254}$ plate; eluted by $7.5 \% \mathrm{KH}_{2} \mathrm{PO}_{4}$ solution with $E$. coli ATCC 25922 at concentration range of streptomycin $150-350 \mu \mathrm{g} / \mathrm{mL}$.

The method resulted a good linearity at $150-350 \mu \mathrm{g} / \mathrm{mL}$ range. The linear equation was $\mathrm{y}=10.176 \mathrm{x}+4.046$. The correlation coefficient $(\mathrm{r}=0.9907)$ and determination of coefficient $\left(\mathrm{r}^{2}=0.9819\right)$ were highly significant. 


\section{Accuracy and precision}

The accuracy was evaluated by the recovery determination of streptomycin sulphate in the injection dosage form and visualized in Figure 3. The mean accuracy was $96.37 \pm 2.22 \%$, with an RSD value of $1.63 \%$.

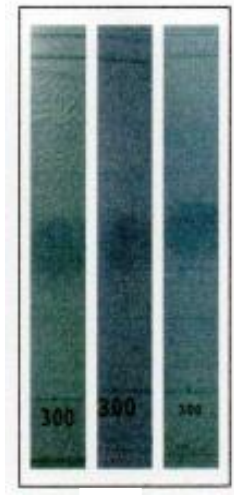

A

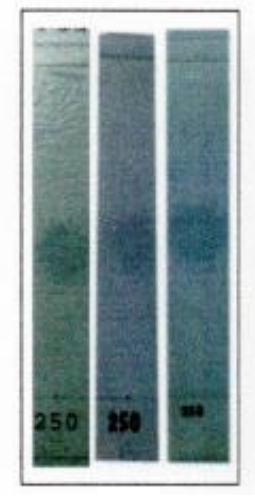

B

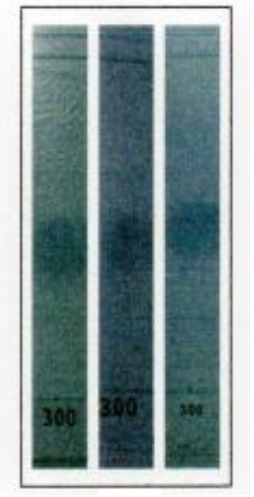

C
Figure 3. Inter day precision observed by bioautography on silica gel $\mathrm{F}_{254}$ plate; developed by $7.5 \% \mathrm{KH}_{2} \mathrm{PO}_{4}$ solution with E. coli ATCC 25922; streptomycin concentration of 250, 300, and 350 $\mu \mathrm{g} / \mathrm{mL}$ performed by three (A, B, C) independent assays.

The analytical method is usually selected based on analysis purposes, such as qualitative, semiquantitative or quantitative. On the other hands, equipments and reagents should be considered for development of accessible and useful the method (Suleimana et al., 2010). In this research, $\mathrm{KH}_{2} \mathrm{PO}_{4}$ solution was used as a single mobile solvent since it is safe, simple and cheaper compare to the organic solvent, such as butanol and methanol.

The $\mathrm{KH}_{2} \mathrm{PO}_{4}$ solution at $7.5 \%$ was then chosen for plate development on the TLC-bioautographic system as recommended by Isnaeni (2005). The lower concentration of the solvent was originally reported by Claes \& Vanderhaeghe (1982), by which the streptomycin could be separated from eight other aminoglycoside antibiotics using $15 \%$ and $10 \%$ aqueous solution of $\mathrm{KH}_{2} \mathrm{PO}_{4}$ at $\mathrm{pH} \quad 4.4$ and 4.5 respectively. This solvent system gave $\mathrm{Rf}$ value of 0.66 and 0.56 respectively. In case of single compound analysis, $7.5 \%$ of $\mathrm{KH}_{2} \mathrm{PO}_{4}$ solution is recommended, but the higher and various concentration are observation needed for mixed compound analyzed.

The agar diffusion or contact bioautography chosen for simplicity reasoning, the technique is carried out in the same manner as common detection of antimicrobial activity or potency by using two layers of agar media.
The chromatogram is placed face down onto the inoculated agar layer incubated by test microorganism (Dewanjee et al., 2015) for a specific period to enable diffusion. Pre-incubation is needed to allow diffusion of the analyte in the chromatogram spot on the surface of agar medium. Then the chromatogram plate was removed from the agar after incubation for certain time.

The Escherichia coli ATCC 25922 was selected as the test microorganism because of its susceptibility to streptomycin, yielding sharply and clearly defined zones of growth inhibition, by which more precise measurements achieved (Susanti et al., 2009).

The validation method was performed according to Wills (2005) for parameter evaluation. Current method is valid and accurate; which appropriate acceptance criteria of $\leq 5 \%$ (ICH, 2005). Thus, the results obtained of the method were close to the true concentration values of the tested samples. The TLC-Bioautography is a analysis method provided for components exhibiting antimicrobial activity, that performed in situ, in comparison with other commonly used antimicrobial susceptibility activity or potency tests. The bio-assay precision of intra-day repeatability determined on the same days with three different test solutions of streptomycin sulphate was gave good results.

\section{CONCLUSION}

Various methods have been developed for the streptomycin determination, but have some disadvantages of being time-consuming and very expensive. The proposed method was found to be rapid, accurate, and repeatable in a hasty manner and techniques. It can be concluded that the simple bioautography detection in thin-layer chromatography with a single solvent system of $7.5 \% \mathrm{KH}_{2} \mathrm{PO}_{4}$ solution pH 4.3 using Escherichia coli ATCC 25922 permitted determination of streptomycin in the injection sample validly.

\section{ACKNOWLEDGEMENTS}

The authors wish to thank Health Laboratory, Surabaya for providing Escherichia coli ATCC 25922 as a test bacterium.

\section{REFERENCES}

Cheng, Z. \& Wu, T. (2013). TLC Bioautography: High Throughput Technique for Screening of Bioactive Natural Products. Combinatorial Chemistry \& High Throughput Screening; 16; 531-49. 
Choma, I. (2005). The Use of Thin-Layer Chromatography with Direct Bioautography for Antimicrobial Analysis. Lc Gc Europe; 18; 482488.

Choma, I. M. \& Edyta, M. G. (2011). Bioautography Detection in Thin-Layer Chromatography. Journal of Chromatography A; 1218; 2684-2691.

Claes, P. J. \& Vanderhaeghe, H. (1982). Thin-layer Chromatographic Identification of Aminoglycoside Antibiotics. Journal of Chromatography; 248; 483-487.

Dewanjee, S., Moumita, G., Niloy, B., Ritu, K. \& Tarun, K. D. (2015). Bioautography and Its Scope in the Field of Natural Product Chemistry. Journal of Pharmaceutical Analysis; 5; 75-84.

Gu, L. H., Liao, L. P., Hu, H. J., Annie, S. W. B., Wang, C. H., Chou, G. X. \& Wang, Z. T. (2015). A Thin-Layer Chromatography-Bioautographic Method for Detecting Dipeptidyl Peptidase IV Inhibitors in Plants. Journal of Chromatography A; 1411; 116-22.

Hormazabal, V. \& Ostensviko. (2013). Determination of Streptomycin and Dihydrostreptomycin in Milk and Meat by Liquid Chromatography-Mass Spectrometry. Journal of Liquid Chromatography \& Related Technologies; 23; 2756-64.

ICH Harmonized Tripartite Guideline. (2005). Validation of Analytical Procedures: Text and Methodology - Q2(R1)-ICH Steering Committee. Geneva: Commission of the European Communities, Geneva.

Isnaeni. (2005). Bioautografi Antibiotika Hasil Fermentasi Mutan Streptomyces Griseus ATCC 10137. Jurnal Farmasi Airlangga; 5; 12-16.

Marston, A. (2011). Thin-Layer Chromatography with Biological Detection in Phytochemistry. Journal of Chromatography A; 1218; 2676-83.

Pendela, M., Jos, H., Ann, V. S. \& Erwin, A. (2009). LC-MS of Streptomycin Following Desalting of a Nonvolatile Mobile Phase and $\mathrm{pH}$ Gradient. Journal of Separation Science; 32; 3418-3424.
Shafqat, U., Arshad, H., Asad, U., Waseem, H. \& Khaliq-ur, R. (2012). Simple and Rapid Method on High Performance Liquid Chromatography (HPLC) for Estimation of Streptomycin Sulphate. World Applied Sciences Journal; 19; 645-49.

Suleimana, M. M., McGaw, L.J., Eloff J. N. \& Naidoo, V. (2010). Detection of Antimicrobial Compounds by Bioautography of Different Extracts of Leaves of Selected South African Tree Species. African Jorunal of Traditional, Complementary and Alternative Medicines; 7; 64-78.

Susanti, M., Isnaeni \& Poedjiarti, S. (2009). Validation of Bioautographic Method for the Determination of Chloramphenicol. Indonesian Journal of Medicine; 1 ; 15-24.

Toman, K. (2004). Toman's tuberculosis Case Detection, Treatment, and Monitoring: Questions and Answers. $2^{\text {nd }}$ ed. Geneva: World Health Organization.

Urszula, H., Krzek, J., Woltyska, H. \& Stachacz, B. (2009). Simultaneous Identification and Quantitative Determination of Selected Aminoglycoside Antibiotics by Thin Layer Chromatography and Densitometry. Journal of AOAC International; 92; 1068-1075.

Whall, T. J. (1981). Determination of Streptomycin Sulfate and Dihydrostreptomycin Sulfate by High-Performance Liquid Chromatography. Journal of Chromatography A; 219; 89-100.

Wills, K. (2005). A Practical Guide to validation. In Easter MC. (Eds.) Rapid Microbiological Methods in the Pharmaceutical Industry. New York: Interpharm/CRC Press. 